Clinical Improvement Interventions for Residents and Practicing Physicians: A Scoping Review of Coaching and Mentoring for Practice Improvement

Casey MacKenzie, MD Candidate, ${ }^{1}$ Teresa M. Chan, MD, MHPE, FRCPC, DRCPSC, ${ }^{2,3}$ and Shawn Mondoux, MD, MSc, FRCPC ${ }^{4}$

\begin{abstract}
Background: Graduate medical education (GME) bodies are beginning to mandate coaching as an integral part of the learning process, in addition to current requirements for mentorship. Once an emergency medicine physician transitions beyond graduate training, there is no requirement and little focus on coaching as a method of improving or maintaining clinical practice. Our objective was to understand and describe the current state of the published literature with regard to the use of coaching and mentorship for both GME and practicing physicians.
\end{abstract}

Methods: We conducted a structured review of the literature through PubMed and Google Scholar and included all articles applying coaching or mentorship modalities to GME trainees or practicing physicians. A Google Form was used for standardized data abstraction. Data were collected pertaining to the settings of intervention, the nature of the intervention, its effect, and its resource requirements.

Results: A total of 3,546 papers were isolated during the literature review. After exclusion, 186 underwent fulltext review by the authors of which 126 articles were included in the final data analysis. Eighty-two articles (65\%) pertained to mentorship and $14(11 \%)$ to coaching; the remainder of the articles discussed a combination or variation of these two concepts. Fifty-three (42\%) articles were descriptive studies and $35(28 \%)$ were narrative reviews or commentaries. Forty-seven (37\%) articles originated from within surgical specialties and coaching was most commonly applied to procedural or manual skills with $22(17 \%)$ instances among all studies.

Conclusions: Most literature on coaching and mentorship is descriptive or narrative, and few papers are in the specialty of emergency medicine. Most interventions are limited to single instances of coaching or mentorship without longitudinal application of the intervention. There is an important need to study and publish further evidence on coaching interventions.

$\mathrm{C}$ oaches have long been used to increase and augment performance. We are familiar with their place in professional sports and business, but it is a burgeoning area in the field of medical education. ${ }^{1-3}$ Coaching in medicine has even made it to the pages of The New Yorker, where attending surgeon Atul Gawande recently wrote about his experiment of employing a coach in the operating room. In his article, Gawande wondered, "Professional athletes use coaches to make sure they are as good as they can be ... so why did I find it inconceivable to pay someone to come into my operating room and coach me on my surgical technique?"4

From the ${ }^{1}$ Michael G. DeGroote School of Medicine and the ${ }^{2}$ Division of Emergency Medicine, Department of Medicine, McMaster University, Hamilton, Ontario; the ${ }^{3}$ McMaster program for Education Research, Innovation, and Theory (MERIT), Hamilton, Ontario; and the ${ }^{4}$ Institute of Health Policy, Management and Evaluation (IHPME), University of Toronto, Toronto, Ontario, Canada.

Received January 15, 2019; revision received March 12, 2019; accepted March 18, 2019.

The authors have no relevant financial information or potential conflicts to disclose.

Supervising Editor: Daniel J. Egan, MD, FACEP.

Address for correspondence and reprints: Shawn Mondoux, MD, MSc, FRCPC; e-mail: shawn.mondoux@medportal.ca. AEM EDUCATION AND TRAINING 2019;3:353-364 
In our field and specialty of emergency medicine, there is little research examining the utility of coaches. In this paper, we sought to understand the state of literature regarding coaching in medical education and translate this to emergency medicine.

\section{Defining Coaching and Mentoring}

Many definitions for coaching are put forward in the literature, ${ }^{5-9}$ and all have very similar elements. Common elements of various nonclinical coaching frameworks include interactions between coach and learner that occur over several observations and time and depend on a trusted respect-based bond; direct contemporaneous observation of practice in the clinical environment; clearly defined and specific areas of analysis and improvement; creation of a cycle of continuous skill/performance improvement in the learner (rather than reach a finite endpoint); encouragement of critical self-reflection and collaborative goal-setting; and feedback and reflections that are timely, specific, actionable, and task-directed. ${ }^{2,5,6}$ There is some debate within the literature about the timeline for coaching, with some advocating for a longitudinal relationship and others noting that it can be time-limited. ${ }^{10}$ Table 1 shows a summary of various definitions of coaching and mentorship in the literature.

When reading on the topic of coaching, however, the historical confusion between mentorship and coaching is worth considering and understanding. Coaching differs from mentorship in that the latter requires no direct observation of skills, is based largely on general advice and guidance, may not frame discussion within the goals of the mentee, and largely uses personal or lived experiences as a method of motivating or guiding learners. ${ }^{5}$ In the period of data collection and analysis for this article, the definition of coaching in the medical context has changed. While experts such as Watling had previously posted a definition of medical coaching on his academic website, subsequent publications ${ }^{9}$ have identified that coaching suffers from a lack of clear definition in the medical literature. As a result, there is some confusion in the field as to what the terms coaching and mentorship mean to us in medicine. ${ }^{9}$ While we must acknowledge that mentorship has had a substantive impact on a number of academic outcomes (e.g., career satisfaction, academic productivity, funding), ${ }^{12-17}$ the use of mentorship in the clinical sphere blurs substantively with the more recent literature on coaching - and hence it is important to bear in mind how this concept might overlap in the clinical environment.

Interestingly, although confusion exists, there has been a large push from major educational bodies to adopt a coaching-type framework. As graduate medical education (GME) accrediting bodies expect a shift toward coaching relationships, understanding how these differ from current training modalities and learner relationships will be important. For instance, the Royal College of Physicians and Surgeons of Canada has recently adopted the new "Competency By Design"

Table 1

Various Definitions of Mentorship and Coaching From the Literature

\begin{tabular}{|c|c|c|c|}
\hline Mentorship (Launer) ${ }^{5}$ & Coaching (Watling) $^{9}$ & Coaching (Deiorio) ${ }^{6}$ & Coaching (Ives) ${ }^{11}$ \\
\hline $\begin{array}{l}\text { - Generally guidance } \\
\text { and support offered } \\
\text { by a more experienced } \\
\text { colleague } \\
\text { - Can arise both formally } \\
\text { and informally } \\
\text { Can cover a broad range } \\
\text { of topics which } \\
\text { include professional and } \\
\text { clinical spheres but } \\
\text { also often include topics } \\
\text { of personal concern } \\
\text { - Generally a private } \\
\text { encounter } \\
\text { Confidentiality is } \\
\text { expected on both sides } \\
\text { Arrangement is } \\
\text { entirely voluntary }\end{array}$ & $\begin{array}{l}\text { - } \text { Mutual engagement } \\
\text { - } \text { toward learner growth } \\
\text { - Embeds bidirectional } \\
\text { reflection } \\
\text { - Acknowledges that } \\
\text { failure as } \\
\text { inevitable and invaluable } \\
\text { - Implied longitudinal } \\
\text { relationship } \\
\text { (which may not be } \\
\text { the case in } \\
\text { the medical education } \\
\text { setting) }\end{array}$ & $\begin{array}{l}\text { - Longitudinal learner } \\
\text { and coach } \\
\text { relationship based in trust } \\
\text { - } \quad \text { Built on respect rather } \\
\text { than friendship } \\
\text { - Should include both } \\
\text { negative and positive } \\
\text { reactions } \\
\text { - Includes the review of } \\
\text { objective assessments } \\
\text { - Coaches help develop } \\
\text { increased self-monitoring } \\
\text { - Explicit creation of goals } \\
\text { - Identification of strategies } \\
\text { to manage existing and } \\
\text { potential challenges } \\
\text { - Improvement of learner } \\
\text { academic performance } \\
\text { - Development of } \\
\text { professional identity }\end{array}$ & $\begin{array}{l}\text { - A systematic process designed to facili- } \\
\text { tate development (change), whether } \\
\text { cognitive, emotional, or behavioral } \\
\text { - Intended for a nonclinical population } \\
\text { - An individualized, tailor-made approach } \\
\text { - Aims to encourage coachees to assume } \\
\text { charge of their life } \\
\text { - Based on the twin growth areas of } \\
\text { awareness and responsibility } \\
\text { - Reliant of the twin skills of listening and } \\
\text { questioning } \\
\text { - Involve a collaborative and egalitarian } \\
\text { relationship, rather than one based on } \\
\text { authority } \\
\text { - Creates a relationship within which the } \\
\text { client agrees to be held accountable for } \\
\text { the choices she makes } \\
\text { - Designed to access the inner resource- } \\
\text { fulness of the client and built on her } \\
\text { wealth of knowledge, experience } \\
\text { - Focused on the achievement of a clear } \\
\text { stated goal, rather than problem analy- } \\
\text { sis }\end{array}$ \\
\hline
\end{tabular}


(CBD) framework, ${ }^{1}$ which involves a heavy emphasis on providing all CBD residents with individualized educational planning via assistance from academic coaches. ${ }^{1}$ This push likely comes from the observation that coaching is seen to be learner-centered and has proven its effectiveness in other domains. ${ }^{9}$

\section{Coaching and the Practicing Physician}

Compared to GME, there is little emphasis on coaching in the realm of continuous professional development. To identify areas of improvement and design interventions, we rely heavily on physician self-assessment, ${ }^{18,19}$ but it is increasingly clear that physicians do not effectively identify opportunities for personal improvement. ${ }^{20}$ Specifically, while physicians are often privy to various forms of practice reports (e.g., peer or multisource feedback, practice analysis reports, and patient reviews), internalizing this information for change and improvement is not ubiquitous. It is possible this is why many have turned to the constructs of coaching or mentorship as methods to overcome this challenge. However, it is unclear if coaching fits the bill in overcoming these challenges to self-improvement - and, despite the lack of evidence observed in the GME landscape, there is high interest in the concept of coaching. ${ }^{4}$

\section{Objectives}

Our primary outcome was to perform a scoping review to understand the current state of the literature of coaching as applied to residents and active practicing physicians. Specifically, we sought to understand what currently exists in the field of medical education as it pertains to effectively improving and/or maintaining competence in clinical practice. Our secondary outcomes were to understand the trends in the literature, as well as the contexts in which the interventions were applied (e.g. specialty, level of training, and clinical environment), their structure of these coaching interventions, the types of skill improvement sought, and the outcomes of the interventions.

\section{METHODS}

\section{Study Design}

We performed this study using the scoping review approach similar to the one described by Arksey and O'Malley. ${ }^{21,22}$ A scoping review was the preferred approach to this concept as our review focused primarily on the assessment of the state of a field of educational work and approaches we called coaching and mentorship rather than a focused question within these fields. This approach offers researchers and scholars a method to map the existing literature, allowing us to

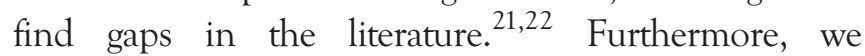
expected the types and quality of these articles to be varied, a scenario best suited to a scoping review. ${ }^{21,22}$

\section{Data Sources and Search Strategy}

With the assistance of a trained health sciences librarian, we conducted an initial search using PubMed in January 2018. We included literature from 1960 to January 15, 2018. The search was limited to English-language papers using "and/or" combinations of the following keywords/phrases: "mentor," "coach," "professional development," "continuing education," "leader coaching," "peer coach," "leader skill development," "continuing professional development," "reciprocal peer coach," "staff development," "career success," "facilitation," "personal development," "surgery," and "medicine." Data Supplement S1, Appendix S1 (available as supporting information in the online version of this paper, which is available at http://onlinelibrary.wiley.com/doi/10. 1002/aet2.10345/full), shows our full search strategy in Boolean and plain-text terminology.

To supplement the results from PubMed, an adjunctive search was performed using Google Scholar as per previously described methods. ${ }^{23-28}$ Google Scholar has been previously shown as a stand-alone alternative search method, which can replace the use of other databases for review papers. ${ }^{29}$ For our Google Scholar search, the keywords "surgeons," "mentor," "coach," "professional development," "continuing education," "leadership," "peer teaching," "faculty," and "skill” were used. We did not specify a time period for publications and accessed all articles resulting from the two searches. Duplicates from the two searches were excluded.

\section{Article Selection and Retrieval}

For the scoping analysis, we included all papers that provided guidance to readers wishing to conduct, report, or write studies on GME coaching in medicine. Our inclusion criterion was that articles had to include participants that were in medical education at a GME level (not only about medical students) or actively practicing. We did not limit the inclusion of articles to EM literature and instead looked more broadly into the general medical and medical education literature. We included commentaries because we wished to be inclusive in our understanding of the scope of the field-many times commentaries on a 
field will include important thought-advancing ideas that can shed light on the ways that the field is moving. We elected to include these, since we know that the concept of coaching is relatively new to medical education and, hence, wanted to capture some of these thoughts and opinions. Exclusion criteria were articles that were concerning only undergraduate medical education or articles that concerned only nonmedical fields.

Title Review. Two investigators (TMC, CKM) performed the literature search and three investigators (TMC, CKM, SM) reviewed titles for relevancy. We ensured inter-rater with our title search, and we independently reviewed titles and then met to calibrate. We set a threshold of a Cronbach's alpha of greater than 0.80 to proceed with our reviewing. Our initial baseline scoring was 0.70 for 75 titles. This triggered a calibration exercise, which was conducted with all three reviewers actively discussing the include and excluded studies from the first group of titles. After calibration, Cronbach's alpha was 0.83 . We then distributed the remainder of the titles evenly among the three reviewers.

Abstract Review. We then reviewed the abstracts of papers that remained after assessing titles. The same inclusion and exclusion criteria were used. Again, inter-rater consistency was done using the same method described above (Cronbach's alpha of 0.82 for 33 citations after a calibration exercise with all three reviewers).

\section{Data Extraction and Analysis}

Following this, we reviewed the full text of the remaining papers that had selected abstracts. These papers were reviewed for inclusion and exclusion criteria as described. We used a Google Form to collect, categorize, and document each paper that met inclusion criteria and passed exclusion criteria. In the design of this paper, three investigators agreed upon what information would be extracted from each study. To ensure consistency between the investigators, two samples were selected to review as a group. The remaining papers were divided equally among the investigators for a final review of the text. For any papers for which a reviewer was unsure, a second reviewer was asked to engage in a review of that same paper. We excluded any papers where we could not obtain the full text via our library or via personal correspondence with the authors.
We extracted the following data on our papers: population of study, country of origin, type of study, number of individuals to which the intervention was applied, reason for the study, specialty and setting, description of the intervention, other interventions simultaneously applied, quantitative and qualitative outcomes described, type of change sought by the authors (cognitive skills, emotional skill, manual skill, etc.), level of implementation, Kirkpatrick level outcomes (level 1-acceptability/satisfaction; level 2knowledge acquisition; level 3-behavioral change; level 4-organizational/systemwide/patient care level outcomes), results of interventional package, and cost of the intervention. ${ }^{30}$ Data extraction elements for each paper are enumerated in Data Supplement S1, Appendix S2.

Thematic Analysis. After data extraction, the papers left for full-text review were further thematically analyzed to examine for key themes and trends. The primary investigator (SM) conducted a content analysis of these remaining papers and presented these themes for triangulation and discussion with the other two members of the research team (CM, TC).

\section{RESULTS}

Our initial search yielded a total of 3,456 papers, 42 of which were immediately excluded as duplicates. Our title and abstract reviews excluded another 2,721 and 589 articles, respectively. We were unable to obtain the full text of eight articles. A total of 186 articles underwent full-text review, of which 60 were further excluded upon review of the entire article. This resulted in a total of 126 articles that were included in our final scoping review and data analysis. Figure 1 shows the flow diagram of our search, selection, and extraction.

Within these final 126 articles, 82 (65\%) papers included content in the area of mentorship, 14 (11\%) on coaching, 15 (12\%) included some variation on mentorship or coaching, nine (7\%) manuscripts fit into the maybe category, and $6(5 \%)$ papers were on both coaching and mentorship. Sixty-three (50.4\%) articles studied populations in the United States and $24(19.2 \%)$ studied populations in Canada. The breakdown of the article types can be seen in Table 2 . An example of those that included a variation of mentorship or coaching include performance feedback interventions $^{31}$ and effectiveness of enhanced peer assessment programs. ${ }^{32}$ 


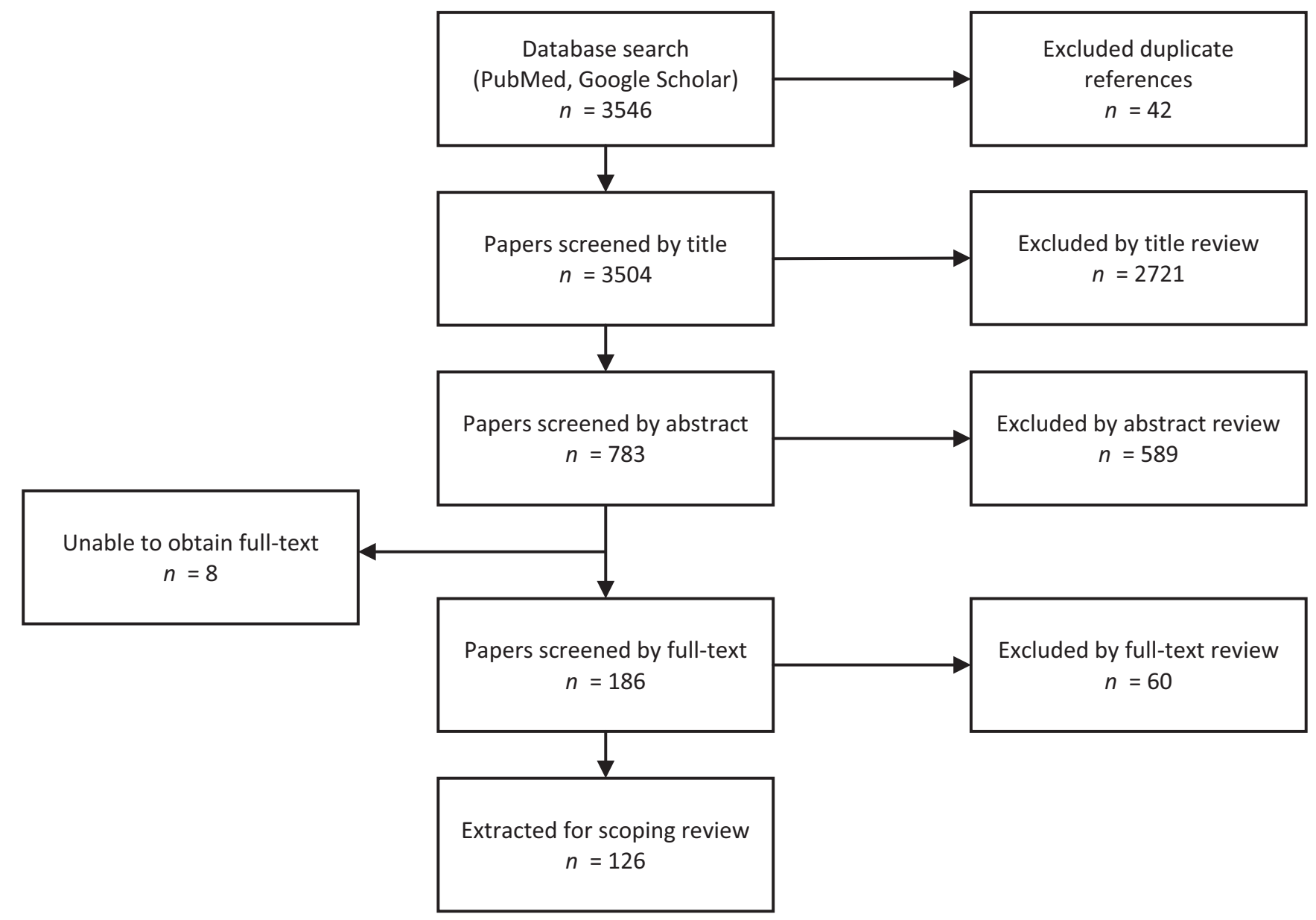

Figure 1. Flow diagram showing the review of literature.

Table 2

Types of Articles Identified in the Scoping Review on Coaching or Mentorship

\begin{tabular}{lrr}
\hline Type of Article & Number of Articles & \% of Total \\
\hline Descriptive studies (minimal evaluation and data) & 52 & 34.2 \\
\hline Commentaries or narrative reviews & 35 & 28.0 \\
\hline Knowledge synthesis (systematic review, narrative review, scoping, meta-analysis) & 12 & 9.6 \\
\hline Survey results & 12 & 5.6 \\
\hline Clarification study (why does this work?) & 3.0 \\
\hline Justification studies & 3 & 2.4 \\
\hline Observational or qualitative studies & 3 & 2.4 \\
\hline Working group or consensus statements & 2 & 1.6 \\
\hline Cognitive engagement as measured by electroencephalogram in OR during observation & & 1 \\
\hline
\end{tabular}

A total of 30 articles (24\%) were targeted to residents exclusively; 52 (41\%) applied only to practicing physicians. Of those papers that discuss practicing physicians, 12 were commentary articles (23\%) and 28 (54\%) were descriptive studies. Four of the studies about practicing physician education were surveys, one study was an observational study, and three were review articles (one white paper on mentorship relationships, one on techniques for surgical coaching, and one systematic review on models for mentorship). Of the descriptive studies, 18 (64\%) originated exclusively from within surgical specialties (no inclusion of any other specialties in the population) and seven of these papers (39\%) were on manual skill acquisition for a specific surgical task.

A variety of specialties were represented in the review, some of which were applied to highly specialized groups such as clinician educators, academic 
Table 3

Coaching Articles and Associated Interventions

\begin{tabular}{|c|c|c|c|}
\hline Classification & Article & Interventions Mentioned & Article Subtype \\
\hline \multirow[t]{12}{*}{ Coaching } & $\begin{array}{l}\text { Palamara K, Kauffman C, Stone VE. Promoting } \\
\text { success: a professional development } \\
\text { coaching program for interns in medicine. J } \\
\text { Grad Med Educ 2015;7:630-7. }\end{array}$ & $\begin{array}{l}\text { Program development, } \\
\text { coach selection and } \\
\text { training, and coachee } \\
\text { perceptions. }\end{array}$ & Descriptive study \\
\hline & $\begin{array}{l}\text { Greenberg CC, Ghousseini HN, Pavuluri } \\
\text { Quamme SR, et al. A statewide surgical } \\
\text { coaching program provides opportunity for } \\
\text { continuous professional development. Ann } \\
\text { Surg 2018;267:868-73. }\end{array}$ & $\begin{array}{l}\text { Statewide implementation } \\
\text { of evidence-based } \\
\text { coaching curriculum. }^{34}\end{array}$ & Descriptive study \\
\hline & $\begin{array}{l}\text { lyasere CA, Baggett M, Romano J, Jena A, } \\
\text { Mills G, Hunt DP. Beyond continuing medical } \\
\text { education: clinical coaching as a tool for } \\
\text { ongoing professional development. Acad } \\
\text { Med 2016;91:1647-50. }\end{array}$ & $\begin{array}{l}\text { Description of the } \\
\text { implementation of a } \\
\text { coaching program. }^{23}\end{array}$ & Descriptive study \\
\hline & $\begin{array}{l}\text { Mutabdzic D, Mylopoulos M, Murnaghan ML, } \\
\text { et al. Coaching surgeons: is culture limiting } \\
\text { our ability to improve? Ann Surg } \\
2015 ; 262: 213-6 \text {. }\end{array}$ & $\begin{array}{l}\text { Study of physician } \\
\text { responses to ideas of } \\
\text { surgical coaching. }\end{array}$ & Descriptive study \\
\hline & $\begin{array}{l}\text { Sekerka LE. Peer coaching as a technique to } \\
\text { foster professional development in clinical } \\
\text { ambulatory settings. J Contin Educ Health } \\
\text { Prof 2003;23:30-37. }\end{array}$ & $\begin{array}{l}\text { Intervention not described. } \\
\text { Study of the perceptions } \\
\text { of coaches and coaches } \\
\text { to educational program. }{ }^{37}\end{array}$ & Clarification study and survey \\
\hline & $\begin{array}{l}\text { van de Wiel MW, Van Den Bossche P, } \\
\text { Janssen S, Jossberger H. Exploring } \\
\text { deliberate practice in medicine: how do } \\
\text { physicians learn in the workplace? Adv Heal } \\
\text { Sci Educ 2011;16:81-95. }\end{array}$ & $\begin{array}{l}\text { Intervention not described. } \\
\text { A survey of how } \\
\text { physicians best learn in } \\
\text { the workplace. }\end{array}$ & Survey \\
\hline & $\begin{array}{l}\text { Sarkiss CA, Philemond S, Lee J, et al. } \\
\text { Neurosurgical skills assessment: measuring } \\
\text { technical proficiency in neurosurgery } \\
\text { residents through intraoperative video } \\
\text { evaluations. World Neurosurg 2016;89:1-8. }\end{array}$ & $\begin{array}{l}\text { Intervention not described. } \\
\text { Development of a "skill } \\
\text { grading score" from peer } \\
\text { coaches. }\end{array}$ & Survey \\
\hline & $\begin{array}{l}\text { Sargeant J, Bruce D, Campbell CM. Practicing } \\
\text { physicians' needs for assessment and } \\
\text { feedback. J Contin Educ Health Prof 2013;33 } \\
\text { Suppl 1:S54-62. }\end{array}$ & $\begin{array}{l}\text { Intervention not described } \\
\text { as the focus. } \\
\text { Commentary on how } \\
\text { assessment and } \\
\text { feedback can guide } \\
\text { CPD. }{ }^{41}\end{array}$ & Commentary \\
\hline & $\begin{array}{l}\text { Deiorio NM, Carney PA, Kahl LE, Bonura EM, } \\
\text { Juve AM. Coaching: a new model for } \\
\text { academic and career achievement. Med Educ } \\
\text { Online 2016;21:1-4. }\end{array}$ & $\begin{array}{l}\text { Intervention not described. } \\
\text { Development of definitions } \\
\text { and academic constructs } \\
\text { for coaching. }\end{array}$ & Commentary \\
\hline & $\begin{array}{l}\text { Linney B. Coach your physicians to care, } \\
\text { listen and connect with patients. Physician } \\
\text { Exec } 2001 ; 27: 36-9 \text {. }\end{array}$ & $\begin{array}{l}\text { Intervention not described. } \\
\text { Commentary on coaching } \\
\text { to improvement } \\
\text { physician/patient } \\
\text { relationship. }{ }^{42}\end{array}$ & Commentary \\
\hline & $\begin{array}{l}\text { Zahid A. Coaching experts: applications to } \\
\text { surgeons and continuing professional } \\
\text { development. Surg Innov 2018;25:77-80. }\end{array}$ & $\begin{array}{l}\text { Intervention not described. } \\
\text { Narrative on coaching to } \\
\text { identify practice gaps. }{ }^{43}\end{array}$ & Commentary \\
\hline & $\begin{array}{l}\text { Peyre SE, FrankI SE, Thorndike M, Breen EM. } \\
\text { Observation of clinical teaching: interest in a } \\
\text { faculty development program for surgeons. J } \\
\text { Surg Educ } 2011 ; 68: 372-6 \text {. }\end{array}$ & $\begin{array}{l}\text { Intervention not described. } \\
\text { Survey on faculty } \\
\text { perceptions of an } \\
\text { observation of teaching } \\
\text { program. }\end{array}$ & Electronic survey \\
\hline
\end{tabular}

(Continued) 


\begin{tabular}{|c|c|c|c|}
\hline Classification & Article & Interventions Mentioned & Article Subtype \\
\hline \multirow[t]{6}{*}{ Coaching and mentorship } & $\begin{array}{l}\text { Beasley HL, Ghousseini HN, Wiegmann DA, } \\
\text { Brys NA, Quamme SRP, Greenberg CC. } \\
\text { Strategies for building peer surgical coaching } \\
\text { relationships. JAMA Surg 2017;152:e165540. }\end{array}$ & $\begin{array}{l}\text { Strategies used by peer } \\
\text { coaches to develop } \\
\text { effective relationships. }\end{array}$ & Descriptive study \\
\hline & $\begin{array}{l}\text { Challacombe B, Kandaswamy R, Dasgupta P, } \\
\text { Mamode N. Telementoring facilitates } \\
\text { independent hand-assisted laparoscopic } \\
\text { living donor nephrectomy. Transplant Proc } \\
\text { 2005;37:613-6. }\end{array}$ & $\begin{array}{l}\text { Telementoring in } \\
\text { laparoscopic kidney } \\
\text { transplant }^{46}\end{array}$ & Descriptive study \\
\hline & $\begin{array}{l}\text { Sargeant J, Lockyer J, Mann K, et al. } \\
\text { Facilitated reflective performance feedback: } \\
\text { developing an evidence- and theory-based } \\
\text { model that builds relationship, explores } \\
\text { reactions and content, and coaches for } \\
\text { performance change (R2C2). Acad Med } \\
\text { 2015;90:1698-706. } \\
\text { Sargeant J, Mann K, Manos S, et al. R2C2 in } \\
\text { action: testing an evidence-based model to } \\
\text { facilitate feedback and coaching in residency. } \\
\text { J Grad Med Educ 2017;9:165-70. }\end{array}$ & $\begin{array}{l}\text { Development of evidence- } \\
\text { based method for } \\
\text { performance feedback. }{ }^{2,3}\end{array}$ & $\begin{array}{l}\text { Descriptive study and then } \\
\text { followed by an empirical study }\end{array}$ \\
\hline & $\begin{array}{l}\text { Yardley S, Westerman M, Bartlett M, Walton } \\
\text { JM, Smith J, Peile E. The do's, don't and } \\
\text { don't knows of supporting transition to more } \\
\text { independent practice. Perspect Med Educ } \\
2018 ; 7: 8-22 \text {. }\end{array}$ & $\begin{array}{l}\text { Intervention not described. } \\
\text { Synthesis of evidence in } \\
\text { supporting physician } \\
\text { transition to practice. }{ }^{47}\end{array}$ & $\begin{array}{l}\text { Knowledge } \\
\text { synthesis - scoping review }\end{array}$ \\
\hline & $\begin{array}{l}\text { Ahmed K, Patel S, Aydin A, et al. European } \\
\text { Association of Urology Section of Urolithiasis } \\
\text { (EULIS) consensus statement on simulation, } \\
\text { training, and assessment in urolithiasis. Eur } \\
\text { Urol Focus 2018;4:614-20. }\end{array}$ & $\begin{array}{l}\text { Intervention not described. } \\
\text { Use of simulation to teach } \\
\text { ureteroscopy. }{ }^{48}\end{array}$ & Consensus statement \\
\hline & $\begin{array}{l}\text { Sachdeva AK, Blair PG, Lupi LK. Education } \\
\text { and training to address specific needs during } \\
\text { the career progression of surgeons. Surg Clin } \\
\text { North Am 2018;96:115-28. }\end{array}$ & $\begin{array}{l}\text { Intervention not described. } \\
\text { Review of new methods to } \\
\text { increase effectiveness of } \\
\text { CME. }\end{array}$ & Commentary \\
\hline
\end{tabular}

Nomenclature using the Cook et al. classification ${ }^{50}$ for medical education studies and other commonly found types of scholarship. $\mathrm{CPD}=$ continuous professional development.

writers, or administrators. Overall, surgical specialties were best represented, exclusively featured in 47 articles (37\%); medicine was exclusively featured in nine (7\%), and 11 (9\%) papers exclusively featured internal medicine or medicine subspecialties. Please note that some articles mentioned multiple specialties. A total of 18 (14\%) articles discussed mentorship generally or applied interventions across many specialties.

\section{Coaching Interventions}

To better understand the variety of coaching interventions described in the literature, papers directly pertaining to coaching or combinations of coaching and mentorship are presented in Table 3. A total of 15 papers fulfill these criteria are include a variety of interventions such as telementoring in surgical settings and statewide implementations of coaching curricula. These range broadly from the application of technology, the use of simulation, the assessment of physician perspectives and the knowledge synthesis studies.

\section{Outcomes in the Coaching and Mentorship Literature}

Table 4 describes that the outcomes sought by the papers we found in our review. Data Supplement S1, Appendix S3, contains a listing all the citations we extracted. Of note, we did not find any empirically based coaching articles that originated within the field of emergency medicine.

Thirty studies (24\%) achieved Kirkpatrick level 1 outcomes, seven (5\%) achieved level 2 outcomes, 12 (10\%) achieved level 3 outcomes, and two (2\%) achieved Kirkpatrick level 4 outcomes. Eighty-five (68\%) were not studies that looked to achieve an outcome and therefore the Kirkpatrick framework could not be applied.

Of the 14 articles that focused on coaching exclusively, five of the articles were commentaries, four were descriptive studies, three were surveys, two were clarification studies, and one article was a knowledge synthesis study. None of these 14 papers on coaching 


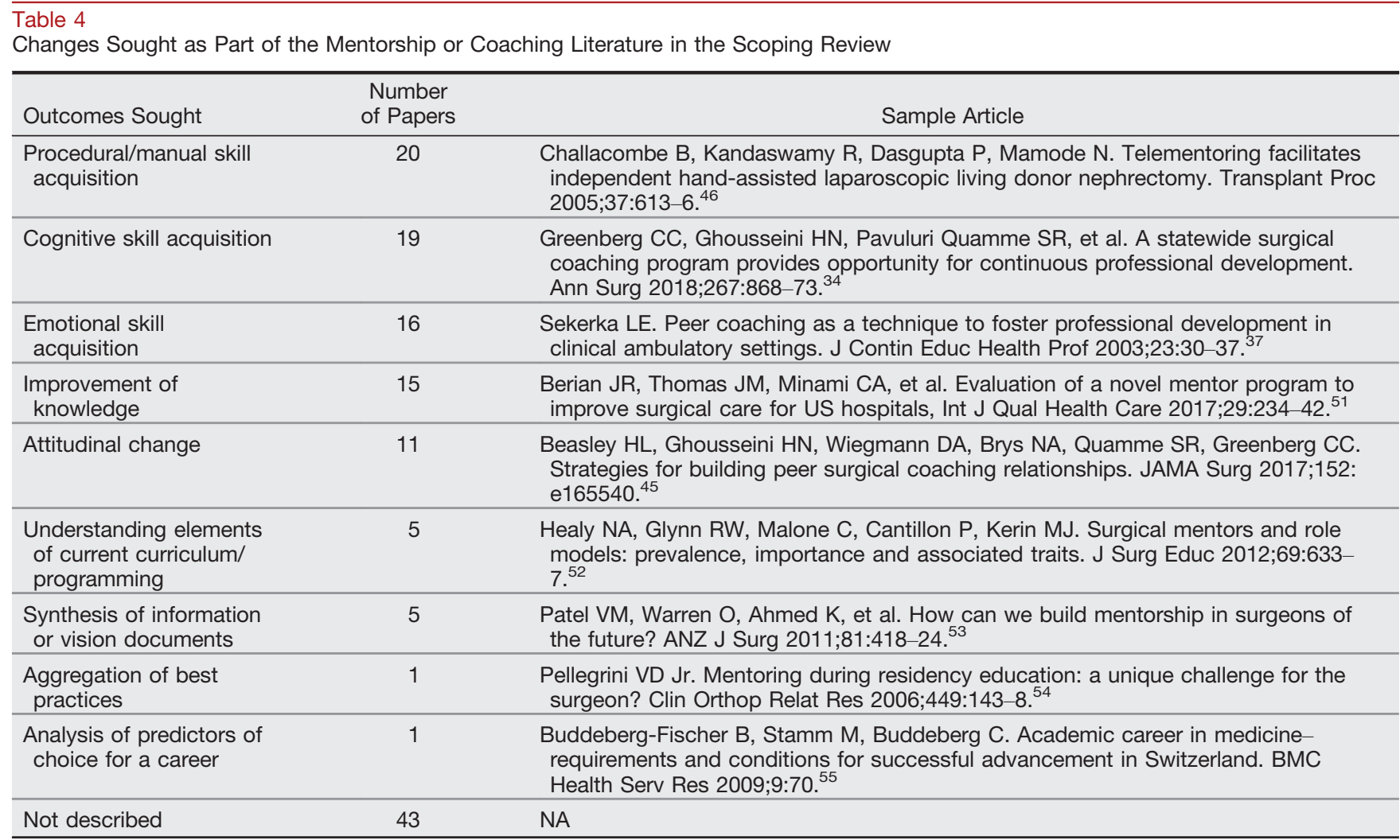

analyzed participants' ability to retain skills or habits over the long term. One paper, by Palamara et al., ${ }^{33}$ contains the largest cohort of coaches and learners with a total of 98 participants. The other descriptive studies were small and contained 35, 31, and 20 participants, respectively.

\section{Thematic Analysis}

\section{Surgeons Are Early Adopters of Coach-} ing. Most coaching articles are attributed to surgical specialties and generally explore the use of coaches to ensure the acquisition of a manual skill. Examples included surgical coaching from specialties such as: urology, ${ }^{46,48}$ neurosurgery, ${ }^{39}$ general surgeons, ${ }^{35,36}$ and multiple other surgical specialties..$^{34,40,44}$ This is perhaps the most logical use of coaches in medicine. Greenberg and colleagues $^{34}$ proposed a statewide surgical coaching model which centered on the review of previously recorded video and direct surgical coaching. Information technology and video conferencing solutions were also broadly applied to allow the coaching surgeon to attend remotely. Specifically, there were very few papers in emergency medicine, with those papers mainly mentioning career and academic mentoring. ${ }^{12,56,57}$

\section{Temporality and Design of Interven-} tions. Within our literature search, there are no papers that reported the results of a longitudinal longterm coaching program within a group of practicing physicians. Furthermore, no paper commented on the design or structure of a sustainable coaching program. Most papers described short-term interventions and skill acquisition and some tested the retention of this skill at a fixed time frame. Additionally, no coaching intervention used an iterative design approach (e.g., plan-do-study-act) to increase satisfaction with and adherence to a coaching framework.

\section{DISCUSSION}

The vast majority of the identified content had mentorship as its main subject area. Descriptive studies and commentaries accounted for most articles. Onethird of all studies originated with surgical specialties describing the acquisition of a procedural or manual skill. A large proportion did not describe what outcome was sought and very few achieved observed and sustained behavior change (i.e., Kirkpatrick ${ }^{30}$ level 3) or any level of organizational impact (i.e., Kirkpatrick 4). ${ }^{30}$ The vast majority did not assess acquisition of skills or abilities in a longitudinal way, at several 
proximal and distal time points, after the intervention was performed.

\section{Confounding Mentorship and Coaching}

To be as inclusive as possible, we attempted to include all papers that referenced both mentorship and coaching. We hypothesized that some authors, citing interventions of mentorship, might also be using coaching modalities. In doing so, we found important and impactful systematic reviews on mentorship in the literature. No strong systematic reviews were found explicit to coaching. In fact, a significant amount of the literature identified in both mentorship and coaching realms were commentaries or narrative reviews. These provide a significant amount of opinion surrounding the optimal use of coaching in medicine but provide little empirical evidence on this topic.

As the literature on coaching evolves, so does the definition of coaching itself. ${ }^{7,9}$ It has been raised by some authors that the traditional definitions of coaching as applied to sports and music are unlikely to be as easily translated to medicine. ${ }^{9}$ This work was published after our literature review and supports the assertion that there is much confusion between notions of feedback, mentorship, and coaching in medical education. A search strategy including mentorship and coaching will be needed until a clear definition is established. The definition used in this paper was put forward by Dr. Watling on his academic webpage, which was no longer available during the peer review process and revisions for this paper. Surprisingly, despite the absence of a clear definition, coaching remains an explicit educational strategy advocated by organizations such as the Royal College of Physicians and Surgeons of Canada. ${ }^{1}$ Future publications on coaching interventions will require an explicit definition as part of their manuscripts until a broadlyagreed-upon definition is established.

When designing and publishing interventions on the topics of coaching or mentorship, authors must insist on more clarity and accuracy in the use of the terms coaching and mentorship. As described by Watling and colleagues, coaching implies an ongoing relationship with the goal of increasing skill. ${ }^{9}$ Their article clearly describes that the desire for longitudinal coaching in medicine seems less than those in other fields, such as music. This is supported by further work in comparing learning expectations between athletes and physicians. ${ }^{7,9}$ To date our field has wrestled with how best to encapsulate the teaching relationships we have in our medical education environments and this has resulted in a rapid evolution of terminology in our literature. However, we feel that adherence to Watling's call for better definitions when discussing coaching interventions might lead to less confusion and overlap in the medical education literature.

When the current state of the literature on coaching and mentoring is considered, most published studies report satisfaction-based outcomes. There is a great opportunity for emergency medicine to enter into this field, since our field is one which allows for direct observation and assessment quite readily (at least in the GME setting). ${ }^{58}$ Future work must go beyond descriptive studies and move to designs that evaluate the acquisition of a skill set. Furthermore, future work must consider longitudinal evaluations that measure both the acquisition and the retention of skill sets when coaching is used as the educational modality. Findings from such studies can then be compared to traditional didactic learning and mentorship with regards to patient-centered outcomes.

\section{LIMITATIONS}

Our scoping review did not explicitly include conference abstracts or the gray literature on this topic. It also excluded textbook chapters and other forms of publication that were not featured in peer-reviewed journals. Some of the knowledge in such texts may be applicable to the design of a longitudinal intervention, which required the application of coaching theory in the clinical environment and should be included when designing such an intervention. Data abstraction was also performed by a single author (SM) with periodic data checks by the remaining authors. Finally, readers are to be reminded that our present synthesis is a scoping review, which is meant to help researchers and scholars map a broad field and look for gaps within the literature base on a topic. The studies included within our review pertain to a broad range of subjects, methods, and outcomes; our summary of the results is not meant for educators to draw any significant conclusions about the efficacy of coaching methods. Finally, due to the lack of clarity in terminology around coaching and mentorship, certain papers, which may have used coachingor mentorship-like strategies (e.g., group peer review and discussion of practice patterns during audit and feedback $^{59}$ ), may have been missed in our present search strategy. 


\section{FUTURE DIRECTIONS}

This paper clearly demonstrates that there is a gap in the medical education literature; to date few studies have properly examined the needs of clinicians, educational modalities, clinical data needs, and sustainability plans in clinical coaching. While coaching is a term that should not merely supplant mentorship or other concepts in medical education, we must work as a field to define the limitations and best usages of this particular instructional strategy.

\section{Needs of Practicing Physicians Versus Trainees}

Many articles have included trainees, faculty members, and other health care workers as part of mentorship or coaching structures. The assumption in many papers is that trainees require competence in specific skills which benefit from training. Some papers surveyed or tested for competence before the intervention. No studies assessed competence throughout the spectrum of their clinicians for targeted recruitment and coaching, nor did any studies assess whether the coaching needs of trainees versus faculty members differed in any meaningful way or described whether the approach to coaching these individuals may differ. Furthermore, there were no papers that described coaching senior members of the faculty in skills that required improvement.

\section{The Relationship Between Coaching and Mentorship}

There is some clear overlap between coaching and mentorship, and this intersection should be further explored. What tensions might lie, for instance, as trainees transition them from needing direct coaching for their day-to-day tasks (e.g., when they are junior residents) to more mentorship in later periods of training (e.g., about supervisory styles of their teaching)? Highquality coaching interventions should adhere to clear, previously outlined definitions of coaching and not blur the lines with mentorship or other teaching strategies. Perhaps more importantly, we must begin establishing evidence that coaching in medicine leads to improved educational outcomes, patient outcomes, and system-level outcomes while simultaneously being able to replicate these interventions in our own jurisdictions. These will provide a strong foundation for current recommendations for increased coaching in graduate-level and faculty education.

\section{CONCLUSION}

There is a paucity of literature on the effectiveness of coaching in medical education and more specifically in emergency medicine. Moving forward the field should focus on proving the effectiveness of coaching interventions on practice change for practicing physicians and residents or organizational improvement for systems or patients. In addition to no clear definition of coaching in medicine, current evidence to support coaching is limited to very few outcomes-oriented studies. Instead, it mainly consists of many descriptive studies and commentaries. Researchers must begin to design interventions and explicitly measure the ability of coaching to address variability in clinical practice (e.g., rates of ordering imaging, adherence to guidelines), attitudes/professionalism, and other patient- or systems-oriented outcomes.

\section{References}

1. CBD and Coaching. Ottawa: The Royal College of Physicians and Surgeons of Canada, 2019. http://www.royalc ollege.ca/rcsite/cbd/implementation/wbas/coaching-and-cbd-e

2. Sargeant J, Lockyer J, Mann K, et al. Facilitated reflective performance feedback: developing an evidence- and theorybased model that builds relationship, explores reactions and content, and coaches for performance change (R2C2). Acad Med 2015;90:1698-706.

3. Sargeant J, Mann K, Manos S, et al. R2C2 in action: testing an evidence-based model to facilitate feedback and coaching in residency. J Grad Med Educ 2017;9:165-70.

4. Gawande A. Personal best: top athletes and singers have coaches. Should you? New Yorker 2011:44-53.

5. Launer J. Supervision, mentorship and coaching. In: Understanding Medical Education: Evidence, Theory and Practice, 2nd ed. Hoboken (NJ): Wiley-Blackwell, 2013. p. 111-22.

6. Deiorio NM, Carney PA, Kahl LE, Bonura EM, Juve AM. Coaching: a new model for academic and career achievement. Med Educ Online 2016;21:1-4.

7. WatlingC, Driessen E, van derVleuten CP, Lingard L. Learning culture and feedback: an international study of medical athletes andmusicians. MedEduc2014;48:713-23.

8. Watling C, Driessen E, van der Vleuten CP, Vanstone M, Lingard L. Music lessons: revealing medicine's learning culture through a comparison with that of music. Med Educ 2013;47:842-50.

9. Watling CJ, LaDonna KA. Where philosophy meets culture: exploring how coaches conceptualise their roles. Med Educ 2019 [Epub ahead of print]. 
10. Simpson D, Holmboe E, Marcdante K, Anderson A, Souza KH. Job roles of the 2025 medical educator. J Grad Med Educ 2018;10:243-6.

11. Ives Y. What is 'coaching'? An exploration of conflicting paradigms. Int J Evid Based Coach Mentor 2008;6:100-13.

12. Yeung M, Nuth J, Stiell IG. Mentoring in emergency medicine: the art and the evidence. Can J Emerg Med 2010;12:143-9.

13. Straus SE, Chatur F, Taylor M. Issues in the mentor-mentee relationship in academic medicine: a qualitative study. Acad Med 2009;84:135-9.

14. Sambunjak D, Straus SE, Marusic A. A systematic review of qualitative research on the meaning and characteristics of mentoring in academic medicine. J Gen Intern Med 2010;25:72-8.

15. Luckhaupt SE, Chin MH, Mangione CM, et al. Mentorship in academic general internal medicine: results of a survey of mentors. J Gen Intern Med 2005;20:1014-8.

16. Donovan A, Donovan A. Views of radiology program directors on the role of mentorship in the training of radiology residents. AJR Am J Roentgenol 2010;194:704-8.

17. Sambunjak D, Straus SE, Marušić A. Mentoring in academic medicine. JAMA 2006;296:1103.

18. Eva K, Regehr G. "I'll never play professional football" and other fallacies of self-assessment. J Contin Educ Health Prof 2008;28:14-9.

19. Eva KW, Regehr G. Self-assessment in the health professions: a reformulation and research agenda. Acad Med 2005;80(10 Suppl):S46-54.

20. Eva KW, Regehr G. Effective feedback for maintenance of competence: from data delivery to trusting dialogues. CMAJ 2013;185:463-4.

21. Arksey H, O'Malley L. Scoping studies: towards a methodological framework. Int J Soc Res Methodol Theory Pract 2005;8:19-32.

22. Pham MT, Rajić A, Greig JD, Sargeant JM, Papadopoulos A, Mcewen SA. A scoping review of scoping reviews: advancing the approach and enhancing the consistency. Res Synth Methods 2014;5:371-85.

23. Iyasere CA, Baggett M, Romano J, Jena A, Mills G, Hunt DP. Beyond continuing medical education: clinical coaching as a tool for ongoing professional development. Acad Med 2016;91:1647-50.

24. Chan TM, Wallner C, Swoboda TK, Leone KA, Kessler C. Assessing interpersonal and communication skills in emergency medicine. Acad Emerg Med 2012;19:1390-402.

25. Thoma B, Camorlinga $\mathrm{P}$, Chan TM, Hall AK, Murnaghan A, Sherbino J. A writer's guide to education scholarship: quantitative methodologies for medical education research (part 1). CJEM 2018;20:125-31.

26. Chan TM, Ting DK, Hall AK, et al. A writer's guide to education scholarship: qualitative education scholarship (part 2). Can J Emerg Med 2018;20:284-92.
27. Hall AK, Hagel C, Chan TM, Thoma B, Murnaghan A, Bhanji $F$. The writer's guide to education scholarship in emergency medicine: education innovations (part 3). CJEM 2018;20:563-70.

28. Murnaghan A, Weersink K, Thoma B, Hall AK, Chan T. The writer's guide to education scholarship in emergency medicine: systematic reviews and the scholarship of integration (part 4). Can J Emerg Med 2018;20:626-33.

29. Gehanno J, Rollin L, Darmoni S. Is the coverage of Google Scholar enough to be used alone for systematic reviews. BMC Med Inform Decis Mak 2013;13:7.

30. Yardley S, Dornan T. Kirkpatrick's levels and education 'evidence'. Med Educ 2012;46:97-106.

31. Kaye AD, Okanlawon OJ, Urman RD. Clinical performance feedback and quality improvement opportunities for perioperative physicians. Adv Med Educ Pract 2014;5:115-23.

32. Wenghofer EF, Way D, Moxam RS, Wu H, Faulkner D, Klass DJ. Effectiveness of an enhanced peer assessment program: introducing education into regulatory assessment. J Contin Educ Health Prof 2006;26:199-208.

33. Palamara K, Kauffman C, Stone VE. Promoting success: a professional development coaching program for interns in medicine. J Grad Med Educ 2015;7:630-7.

34. Greenberg CC, Ghousseini HN, Pavuluri Quamme SR, et al. A statewide surgical coaching program provides opportunity for continuous professional development. Ann Surg 2018;267:868-73.

35. Mutabdzic D, Mylopoulos M, Murnaghan ML, et al. Coaching surgeons: is culture limiting our ability to improve? Ann Surg 2015;262:213-6.

36. $\mathrm{Hu}$ Y, Peyre SE, Arriaga AF, et al. Postgame analysis: using video-based coaching for continuous professional development. J Am Coll Surg 2012;214:115-24.

37. Sekerka LE. Peer coaching as a technique to foster professional development in clinical ambulatory settings. J Contin Educ Health Prof 2003;23:30-37.

38. van de Wiel MW, Van Den Bossche P, Janssen S, Jossberger $\mathrm{H}$. Exploring deliberate practice in medicine: how do physicians learn in the workplace? Adv Heal Sci Educ 2011;16:81-95.

39. Sarkiss CA, Philemond S, Lee J, et al. Neurosurgical skills assessment: measuring technical proficiency in neurosurgery residents through intraoperative video evaluations. World Neurosurg 2016;89:1-8.

40. Min H, Morales DR, Orgill D, Smink DS, Yule S. Systematic review of coaching to enhance surgeons' operative performance. Surgery 2015;158:1168-91.

41. Sargeant J, Bruce D, Campbell CM. Practicing physicians' needs for assessment and feedback. J Contin Educ Health Prof 2013;33(Suppl 1):S54-62.

42. Linney B. Coach your physicians to care, listen and connect with patients. Physician Exec 2001;27:36-9. 
43. Zahid A. Coaching experts: applications to surgeons and continuing professional development. Surg Innov 2018;25:77-80.

44. Peyre SE, Frankl SE, Thorndike M, Breen EM. Observation of clinical teaching: interest in a faculty development program for surgeons. J Surg Educ 2011;68:372-6.

45. Beasley HL, Ghousseini HN, Wiegmann DA, Brys NA, Quamme SR, Greenberg CC. Strategies for building peer surgical coaching relationships. JAMA Surg 2017;152:e165540.

46. Challacombe B, Kandaswamy R, Dasgupta P, Mamode N. Telementoring facilitates independent hand-assisted laparoscopic living donor nephrectomy. Transplant Proc 2005;37:613-6.

47. Yardley S, Westerman M, Bartlett M, Walton JM, Smith J, Peile E. The do's, don't and don't knows of supporting transition to more independent practice. Perspect Med Educ 2018;7:8-22.

48. Ahmed K, Patel S, Aydin A, et al. European Association of Urology Section of Urolithiasis (EULIS) consensus statement on simulation, training, and assessment in urolithiasis. Eur Urol Focus 2018;4:614-20.

49. Sachdeva AK, Blair PG, Lupi LK. Education and training to address specific needs during the career progression of surgeons. Surg Clin North Am 2018;96:115-28.

50. Cook DA, Bordage G, Schmidt HG. Description, justification and clarification: a framework for classifying the purposes of research in medical education. Med Educ 2008;42:128-33.

51. Berian JR, Thomas JM, Minami CA, et al. Evaluation of a novel mentor program to improve surgical care for US hospitals. Int J Qual Health Care 2017;29:234-42.

52. Healy NA, Glynn RW, Malone C, Cantillon P, Kerin MJ. Surgical mentors and role models: prevalence, importance and associated traits. J Surg Educ 2012;69:633-7.
53. Patel VM, Warren O, Ahmed K, et al. How can we build mentorship in surgeons of the future? ANZ J Surg 2011;81:418-24.

54. Pellegrini VD Jr. Mentoring during residency education: a unique challenge for the surgeon? Clin Orthop Relat Res 2006;449:143-8.

55. Buddeberg-Fischer B, Stamm M, Buddeberg C. Academic career in medicine-requirements and conditions for successful advancement in Switzerland. BMC Health Serv Res 2009;9:70.

56. Regehr G, Bandiera G, Leblanc C, et al. Education scholarship in emergency medicine part 2: supporting and developing scholars. CJEM 2014;16(Suppl 1):S6-12.

57. Love JN, Coates WC, Santen SA, Hobgood CD, Mavis BE, Farrell SE. The MERC at CORD scholars program in medical education research: a novel faculty development opportunity for emergency physicians. Acad Emerg Med 2009;16 Suppl 2:S37-41

58. Colmers-Gray IN, Walsh K, Chan TM. Assessment of emergency medicine residents: a systematic review. Can J Med Educ 2017;8:e106-22.

59. Cooke LJ, Duncan D, Rivera L, Dowling SK, Symonds C, Armson H. How do physicians behave when they participate in audit and feedback activities in a group with their peers? Implement Sci 2018;13:104.

\section{Supporting Information}

The following supporting information is available in the online version of this paper available at http:// onlinelibrary.wiley.com/doi/10.1002/aet2.10345/full

Data Supplement S1. Supplemental material. 